Puede citar este artículo como:

GIL GuIRADO, Salvador, «Deconstruyendo riesgos. Cuatro siglos de cambios en la vulnerabilidad y adaptación a las inundaciones y sequías en Murcia», Revista de Historia Moderna. Anales de la Universidad de Alicante, n. ${ }^{\circ} 35$ (2017), pp. 308-344, DOI: 10.14198/RHM2017.35.09.

\title{
DECONSTRUYENDO RIESGOS. CUATRO SIGLOS DE CAMBIOS EN LA VULNERABILIDAD Y ADAPTACIÓN A LAS INUNDACIONES Y SEQUÍAS EN MURCIA*
}

\author{
SALVADOR Gil GUIRADO \\ Universidad de Murcia \\ salvador.gill@um.es
}

\section{Resumen}

Pocos aspectos tienen mayor relevancia que los destinados a mejorar la seguridad de las personas, máxime en un contexto de cambio global en que los desastres naturales y el número de personas afectadas aumentan año a año.

Este escenario hace necesario reducir la vulnerabilidad y mejorar la estrategia de adaptación y resiliencia de las sociedades. Para esto es necesario tener en cuenta tanto criterios ambientales, como perceptuales, culturales e históricos. Una forma de sacar las lecciones que nos brinda nuestra historia, es valorar la vulnerabilidad secular ante dos de los principales riesgos que afectan a las sociedades: las inundaciones y las sequías.

En este trabajo se aplica el Índice de Cambios Perceptuales a los Riesgos Climáticos (ICPRC) en Murcia desde el siglo XVII. Los resultados muestran una mejora de la percepción del peligro y que la vulnerabilidad, a pesar de haber descendido, sigue siendo alta, en parte porque la estrategia de adaptación se basa en las grandes obras de ingeniería y no se ponen límites a la exposición de bienes y personas.

Palabras clave: vulnerabilidad, resiliencia, adaptación, inundaciones, sequías, percepción.

\footnotetext{
* Este trabajo ha sido realizado gracias a la financiación de la Fundación Seneca (Agencia de Ciencia y Tecnología de La Región de Murcia) a través de una Beca Contrato Predoctoral de Formación de Personal Investigador percibida por el autor durante el periodo 2009/2013 (Expediente: 09498/FPI/08).
} 


\begin{abstract}
Deconstructing risks. Four centuries of changes in vulnerability and adaptation to floods and drought in Murcia.

In a context of global change in which natural disasters and the number of people affected increase every year, few aspects are more relevant than those that are intended to improve security of people. This scenario makes it necessary to reduce vulnerability and improve the adaptation and resilience strategy of societies. In order to do so, it is necessary to consider on the one hand, environmental criteria and on the other hand, perceptual, cultural and historical criteria. One way to draw lessons from our history is to assess the secular vulnerability of floods and droughts. In this work the Index of Perceptual Changes to Climate Risks (ICPRC) has been applied in Murcia from the seventeenth century to now. The results show an improvement in the hazard perception. In addition, the vulnerability, despite having fallen, remains high, due to the adaptation strategy is based on large engineering works and there are no clear limits to the exposition of goods and people.
\end{abstract}

Keywords: vulnerability, resilience, adaptability, floods, droughts, risk perception.

\title{
1. Introducción
}

El estudio de los eventos extremos cobra especial importancia en la actualidad, tras la constatación de que el aumento de las emisiones de gases de efecto invernadero está produciendo unas claras modificaciones en el ciclo hidrológico y originando una importante variación en la distribución de las precipitaciones ${ }^{1}$. La consecuencia más inmediata y crítica la supone el incremento en la intensidad de las precipitaciones extremas ${ }^{2}$ y la mayor recurrencia de las sequías, siendo los países mediterráneos especialmente propensos a este escenario ${ }^{3}$.

La alteración climática actual, junto con la mayor exposición de bienes y personas ${ }^{4}$, está dando lugar a un desacople entre la adaptación de los sociedades y su entorno. Esta situación es sintomática de sociedades vulnerables que no se protegen adecuadamente ante el peligro natural. El panorama se vuelve más desolador si consideramos que las proyecciones de los modelos

\footnotetext{
1. SCHIERMEIER, 470/7334 (2011): 316. FIELD, 2012.

2. MiN et al., 470/7334 (2011): 378-381.

3. PRUDHOMME et al., 111/9 (2014): 3262-3267.

4. BARREDO, 9 (2009): 97-104.
} 
predicen que el escenario climático propenso a generar situaciones de peligro irá en aumento ${ }^{5}$. En este contexto, el estudio histórico de los eventos naturales extremos, posibilita extraer lecciones del pasado aplicables en la gestión actual de los riesgos climáticos.

Son numerosos los trabajos que hablan de la necesidad de aprender del pasado para entender la relación sociedad-medio actual y futura ${ }^{6}$, así como de los riesgos asociados a esta relación cambiante ${ }^{7}$. Sin embargo, son escasos los intentos de aplicar esta perspectiva mediante el establecimiento de metodologías estandarizadas. En este sentido, las mejores aproximaciones se han producido desde la arqueología y la geoarqueología, con un claro componente histórico-determinista ${ }^{8}$. Sin embargo, las relaciones entre clima y sociedad en estos trabajos están extraídas de testigos ambientales, dejando en un segundo lugar el análisis de la percepción social que posibilita el estudio de documentos históricos.

Algunos trabajos han incidido en esta línea histórico-documental ${ }^{9}$, aunque aún adolecen de un método estandarizado que permita aplicar los estudios a diversas regiones del planeta y a distintos periodos.

Otra vertiente investigadora totalmente diferenciada, hace referencia a los modelos de medición de la vulnerabilidad para periodos recientes ${ }^{10}$. Sin embargo estos modelos, se muestran escasamente adaptados a la concepción integral de los sistemas humanos y ambientales. Las diferencias de fondo entre la mayoría de estos modelos estriban en la escala de estudio, que por lo general oscila entre local, regional o nacional ${ }^{11}$. Pero la mayoría presenta la misma dependencia de una gran cantidad de datos cuantitativos que dificultan su extrapolación a otros espacios y épocas. Esta situación, genera que regiones donde no existe una cobertura amplia de este tipo de datos

5. HiRABAYASHI et al., 53/4 (2008): 754-772.

6. MESSERli et al., 19/1-5 (2000): 459-479. Alberola RomÁ y OlCina CanTOS, 2009. GilGuIRADO, ESPÍN SÁNCHEZ y PRIETO, 139/2 (2016):183-200.

7. Alberola Romá, 39/2 (2009):105-125. Endfield, 109/10 (2012): 3676-3681. MCMICHAEL, 109/13 (2012):4730-4737.

8. Mächtle y Eitel, 103 (2013):62-73. HSiang y Burke, 123/1 (2014): 39-55.

9. Messerli et al., op. cit. ENDFIELD, 83 (2007): 9-38. GÓMEZ BAGGETHUN et al., 22/3 (2012): 640-650.

10. Cutter, Boruff y SHirley, 84/2 (2003): 242-261. BirkMANn, 2007.

11. BIRKMANN, 2007. 
(fundamentalmente los países en vías de desarrollo) queden al margen de los estudios de riesgos naturales y vulnerabilidad ${ }^{12}$.

Esta situación hace necesaria una vía de investigación que integre los modelos cuantitativos de medición de la vulnerabilidad con los de análisis del contexto social e histórico. Esta nueva vía posibilitaría disponer de resultados comparables en el espacio y el tiempo y extraer lecciones del pasado aplicables a la gestión de riesgos en la actualidad.

Este trabajo incorpora la percepción del riesgo junto con los factores sociales y ambientales en el estudio de eventos de sequía e inundación en Murcia. Para ello se propone el Índice de Cambios Perceptuales a los Riesgos Climáticos (ICPRC), que agrupa varios indicadores para analizar la evolución de la vulnerabilidad y adaptación a inundaciones y sequías desde el siglo XVII hasta nuestros días.

\subsection{Red conceptual en el análisis de riesgos naturales en perspectiva histórica}

Existe consenso en que el riesgo de padecer un determinado evento natural adverso está determinado por la suma de tres factores básicos que integran este sistema dinámico. Siendo el riesgo final consecuencia directa de la suma de la peligrosidad, la exposición y la vulnerabilidad ${ }^{13}$.

El riesgo es el umbral de cambio tolerable que se ve sobrepasado en un plazo más o menos breve y provoca el desencadenamiento de una situación que conduce a una catástrofe ${ }^{14}$. La peligrosidad hace referencia al propio proceso natural susceptible de generar daños en la sociedad o el propio medio natural ${ }^{15}$. La exposición es la cantidad de bienes a preservar capaces de ser dañados ante un peligro natural ${ }^{16}$. Finalmente, la vulnerabilidad, es la pérdida esperable de un bien expuesto. Esta puede ser vulnerabilidad humana, estructural, institucional, económica, ecológica, etc. Esa multitud de características internas y externas cabe definirlas como vulnerabilidad global ${ }^{17}$.

12. TAPSELL et al., 360/1796 (2002): 1511-1525.

13. CARDONA et al., 2012: 65-108.

14. Calvo García-TORNEL, 2001.

15. Olcina Cantos, 12/270 (2008).

16. Calvo García-Tornel, op. cit.

17. Wilches-ChAuX, 1993: 22. 
Sin embargo, la compleja red de interconexiones entre las variables sociales y ambientales que intervienen en los procesos de riesgo, requiere conceptos explicativos adicionales, tales como la resiliencia y la adaptabilidad. Folke ${ }^{18}$ define la resiliencia como la capacidad de un sistema para absorber impactos y luego reorganizarse. La adaptación aplicada a los sistemas humanos puede definirse como la capacidad de los grupos o personas para mejorar y añadir nuevos métodos con los que hacer frente a las condiciones medioambientales en base a su repertorio cultural ${ }^{19}$. Las modalidades y distintos tipos de adaptación son puntos claves a tener en cuenta, ya que son manifestaciones de la capacidad de adaptación y representan la forma de reducir la vulnerabilidad ${ }^{20}$.

La estrategia de resiliencia y adaptación de los sistemas socioambientales engloba los conceptos anteriores, puesto que según Adger y otros ${ }^{21}$ esta estrategia puede concebirse como la forma en que estos sistemas son capaces de auto-organizarse para recuperarse y al mismo tiempo desarrollar la capacidad de aprendizaje y adaptación.

De todos estos factores, la medición de la vulnerabilidad es la que entraña mayores dificultades. No en vano, tal y como señala García Acosta ${ }^{22}$, el riesgo natural es una construcción social y las respuestas sociales no se prestan fácilmente a estandarización. En este sentido, la percepción humana del peligro y de la propia vulnerabilidad, determina la vulnerabilidad final de cada sociedad ${ }^{23}$.

De esta manera, la incorporación de la percepción en los estudios de riesgo, es un asunto de capital importancia. Una definición de la percepción del riesgo puede extraerse de las palabras de Sauri ${ }^{24}$, al señalar que «la capacidad de respuesta viene determinada en gran parte por la percepción del problema y especialmente por la (falsa) sensación de seguridad que pueden proporcionar las tecnologías estructurales de control del fenómeno físico». Por lo tanto, la percepción está directamente relacionada con la vulnerabilidad ${ }^{25} \mathrm{en}$ la

\footnotetext{
18. FOLKE, 16/3 (2006):253-267

19. O'BRIEN y HOLLAND, 57/1 (1992): 36-69.

20. SMIT y WANDEL: 16/3 (2006): 282-292.

21. ADGER et al., 309/5737 (2005): 1036.

22. GARCía ACOSTA, 19 (2005):1-24.

23. SAURí et al., 51-52 (2010):269-278.

24. SAURÍ, 23 (2003): 18.

25. RIBAS Y SAURÍ, 2006: 285-300.
} 
medida en que, las diferentes percepciones ante el peligro, modelan, modulan o mitigan la vulnerabilidad, tanto de cada individuo, como del conjunto de la sociedad.

\subsection{La difuminación espacio-temporal de las sequías. Un problema para delimitar su impacto}

La sequía es el riesgo natural que afecta a más personas y a regiones más amplias en el mundo, difiere del resto por la dificultad para predecir y delimitar su inicio, su final y el ámbito exacto al que afecta ${ }^{26}$. Al igual que las inundaciones, las actividades humanas por sí solas pueden generar un evento tipificado como sequía.

La Organización Meteorológica Mundial27, define la sequía como una deficiencia sostenida y extendida en el tiempo de las precipitaciones. Generalmente se distinguen cuatro tipos distintos ${ }^{28}$ :

- Sequía meteorológica o climática, que sucede cuando durante un intervalo de tiempo definido las precipitaciones o niveles de humedad son inferiores a la media en una cantidad previamente definida.

- Sequía hidrológica se produce cuando la reducción de la precipitación durante un periodo prolongado acaba afectando a los recursos hídricos superficiales y/o subterráneos.

- Sequía agrícola, se produce cuando el déficit en la disponibilidad de agua para las plantas acaba afectando a su desarrollo.

- Sequía socioeconómica, tiene lugar cuando el agua disponible no permite satisfacer las demandas normales en un sistema económico. Guarda una relación directa con las anteriores, especialmente con la hidrológica, pero no siempre es necesaria una situación climática desencadenante para su desarrollo.

Estas diferencias se pueden entender como un progreso dentro del desarrollo del evento. Así, la primera manifestación es la sequía meteorológica o climática, que de seguir, acaba convirtiéndose en una sequía agrícola y

26. SÖNMEZ et al., 35/2 (2005): 246.

27. WMO, 1986.

28. Wilhite y GLANTZ, 10/3 (1986): 114.

Revista de Historia Moderna, n. ${ }^{\circ} 35$ (2017) (pp. 308-344) | ISSN-e: 1989-9823 | ISSN: 0212-5862 
cuando se prolonga durante un largo periodo puede convertirse en una sequía hidrológica.

Sin embargo, la complejidad para cuantificar los impactos de los diferentes tipos de sequía es tal que no existe un criterio universalmente válido con el poder medir este fenómeno y acotarlo en el tiempo y el espacio.

En este trabajo, a través del método propuesto (ICPRC) se pretende incidir en los aspectos sociales de las sequías.

\subsection{El impacto espasmódico de las inundaciones}

Las inundaciones por su manifestación repentina y acotada a un espacio definido, tienen una más fácil delimitación que las sequías. Las inundaciones suelen entenderse como un desbordamiento de las aguas hacia afuera de los márgenes estables de un cuerpo de agua (lagos, ríos, embalse, océanos), de ahí los problemas que son susceptibles de generar. Esta característica, las diferencia etimológicamente de las crecidas, por cuanto en estas no necesariamente se producen anegamientos de terrenos, aunque muchas veces se usen como sinónimo. Cuando se refieren a inundaciones en los ríos, poseen varios términos ciertamente equivalentes, los más extendidos son aluvión, riada y avenida.

Es evidente que las actividades humanas son responsables del impacto y desencadenamiento de algunas inundaciones. A la mala previsión o diseño fallido de infraestructuras, cabe añadir actividades como la impermeabilización de terrenos naturales que aceleran la escorrentía, la tala abusiva de masa vegetal que disminuye la capacidad de retención del terreno, la extracción de materiales, etc.

El estudio de la vulnerabilidad ante inundaciones con una estrategia encaminada a reducir sus efectos perniciosos es una cuestión imperiosa, ante la constatación de que es uno de los riesgos que más víctimas e impactos provoca a nivel global ${ }^{29}$. Si bien, en vez de culpabilizar de forma indirecta a la naturaleza, parece más acertado señalar a la mala gestión y al aumento de la exposición como principales responsables de estos daños crecientes.

29. PÉREZ-MORALES et al., 2015. 


\section{Factores de peligrosidad y vulnerabilidad en el área de estudio}

El actual término municipal de Murcia ocupa $885,5 \mathrm{~km}^{2}$ y tiene una población de 439.889 habitantes, cifra que supone cuatro veces más que en 1900. Sin embargo, en el espacio del Valle del Río Segura ocupado por la ciudad se produce un patrón de continuidad en el comportamiento social, más allá de fronteras administrativas. Este sería el espacio identificado como el Área Metropolitana de Murcia, que engloba otros seis municipios cercanos (Alcantarilla, Santomera, Beniel, Molina de Segura, Las Torres de Cotillas, Alguazas, Lorquí y Ceutí) con una extensión conjunta de $1.183,4$ km² y una población de 626.539 habitantes en $2015^{30}$. Su agrupación obedece, en esencia, a criterios de naturaleza funcional y de relaciones cotidianas de la población residente ${ }^{31}$. Este territorio que representa un continuo histórico y espacial, va más allá de las divisiones político-administrativas y se extiende desde Molina de Segura, pasando por Alcantarilla, Murcia y Beniel, hasta enlazar con la huerta de la cercana ciudad de Orihuela (Figura 1).

Fig. 1. Mapa de la región ambiental e histórica de la Huerta de Murcia (1810?)

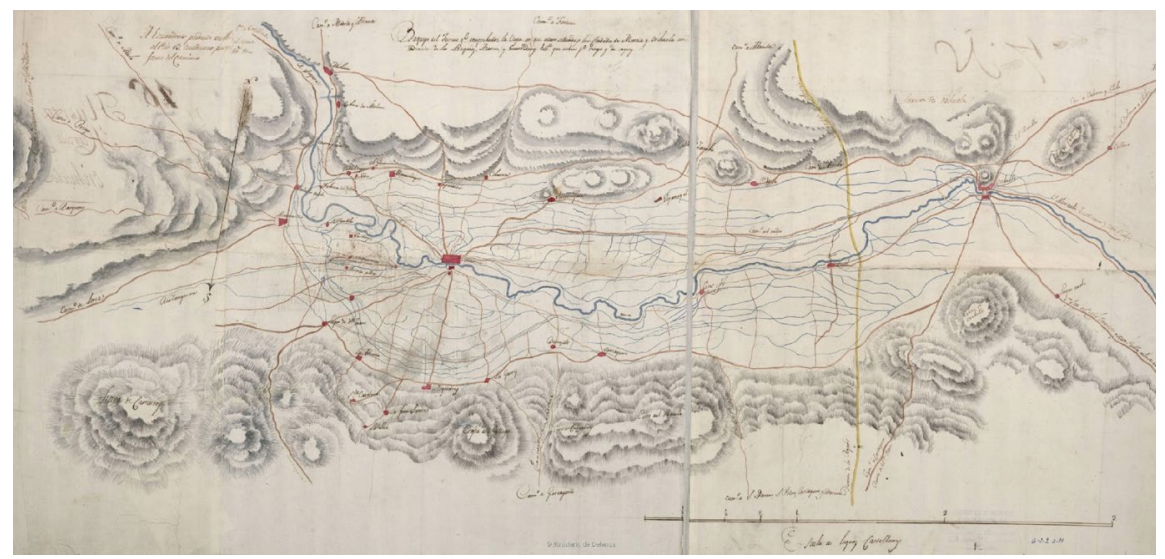

Fuente: Cartoteca del Archivo General Militar de Madrid. MECD, 2012.

30. CREM, 2016.

31. SerRano Martínez y GonZÁLEZ ORTiz, 2007: 492. 
2.1. La condición surestina como factor de peligrosidad a las sequías e inundaciones

La ciudad de Murcia participa de una unidad climática diferenciada del resto de climas de la Península Ibérica, asociándose a esta con el Sureste de España, caracterizado a su vez por la aridez, la irregularidad de las precipitaciones, la acusada sequía estival, la elevada evapotranspiración y las altas cifras de insolación. Aspectos que motivan una aridez climática, pero también edáfica, sin parangón a nivel europeo.

Sin duda, es la irregularidad de las precipitaciones la característica más destacable y definitoria de la región del Sureste. Determinando que para el imaginario colectivo, pensar en esta zona, suponga entre otras cosas, aludir a la escasez de lluvias y también a las graves inundaciones.

El concepto Sureste tiene un significado sociológico percibido desde hace siglos, pero extendido en la última centuria y generalizado a partir de la pasada década de los años sesenta tras la puesta en marcha de los estudios técnicos para llevar a cabo el Trasvase Tajo-Segura. Momento en que, desde la ciencia geográfica comenzaron a extenderse los trabajos relacionados con este espacio de cara a caracterizar y legitimar su unidad bajo criterios climáticos ${ }^{32}$.

No obstante, la delimitación climática del Sureste está sujeta a variaciones, dependiendo del criterio taxonómico aplicado. Sin embargo, puede considerarse cierta unanimidad al considerar que las precipitaciones por si solas no marcan la diferencia. De esta manera, parece claro que el límite del Sureste climático lo integran aquellas tierras donde las precipitaciones son inferiores a los $400 \mathrm{~mm}$ anuales, la evapotranspiración es superior a $1.000 \mathrm{~mm}$ anuales y no hay meses con temperatura media inferior a $\operatorname{los} 8{ }^{\circ} \mathrm{C}^{33}$.

Entre los factores que explican las condiciones climáticas sobresalen: la circulación general atmosférica, insertada en las latitudes medias en la fachada occidental del macrocontinente euroasiático; la proximidad a un mar cálido como el Mediterráneo; la cercanía del continente africano; y la posición a sotavento de los relieves béticos. Este último factor, es el principal causante de los largos periodos de sequía, a su vez, el mar Mediterráneo es el responsable máximo de las lluvias torrenciales otoñales y la proximidad del continente

32. GEIGER, 7/1-2 (1973):166-209.

33. Gil Olcina, 17 (1995a): 72.

Revista de Historia Moderna, n. ${ }^{\circ} 35$ (2017) (pp. 308-344) | ISSN-e: 1989-9823 | ISSN: 0212-5862 
africano recrudece aún más las tórridas temperaturas estivales, atemperadas ya por las cálidas aguas mediterráneas.

\subsection{La sociedad murciana y las estructuras de poder: estoicismo, conservadurismo y temor al cambio}

A lo largo de los siglos, en la ciudad de Murcia la gestión del riesgo de sequía e inundación ha sido dependiente de una organización férrea y ligada a unas estructuras sociales estables. Esta situación ha motivado el arraigo del tradicionalismo y conservadurismo entre la población murciana y sus dirigentes. Braudel ${ }^{34}$ relacionaba los sistemas sociales rígidos y dictatoriales con los espacios de regadío antiguo. A pesar de no estar clara esta relación, en Murcia parecen coincidir la amenaza constante del riesgo y la especialización agrícola, con la ausencia, excepto agitaciones puntuales, de un movimiento social subversivo de base obrera durante los siglos XIX y $\mathrm{XX}^{35}$.

La falta de revueltas sociales destacables, a pesar de ser un contexto continental propicio para ello, revela el carácter tradicional, el miedo al cambio, la falta de incentivos y la escasa formación de la masa poblacional murciana, que lejos de sublevarse, se conformaba estoicamente ante lo que consideraba lo inevitable de la vida agraria, limitada por abajo por la propiedad de la tierra y por arriba por el azar de la naturaleza.

Sin embargo, en Murcia sí se produce una lucha de poder entre las clases dirigentes que se acentúa con el discurrir de los siglos. Tras las revoluciones liberales decimonónicas, las desamortizaciones y la abolición del diezmo de manera oficial en 1837, se confirma que esta batalla la pierde la iglesia a favor de una nueva burguesía. Por otro lado, el poder municipal secularmente se enfrentaba y competía con el eclesiástico, el real e incluso el señorial, para salvaguardar los intereses generales de la población, sin ningún otro tipo de contrapartida aparente. A este respecto, son constantes las disputas entre el Cabildo Municipal y el Eclesiástico en cuanto a la celebración, tipo, coste y necesidad de rogativas pro-serenitate y pro-pluvia. Por otro lado, son frecuentes los casos en que el concejo de Murcia anteponía, en algunos aspectos, el bienestar social y el mantenimiento de la entidad de la ciudad, a los privilegios de clase.

34. BRAUDEL, 1984.

35. Pérez Picazo, Lemeunier y Chacón Jiménez, 1980: 26.

Revista de Historia Moderna, n. 35 (2017) (pp. 308-344) | ISSN-e: 1989-9823 | ISSN: 0212-5862 


\section{Fuentes de datos usadas para el análisis de las inundaciones y sequías históricas en Murcia}

La metodología aplicada en este trabajo se nutre fundamentalmente de fuentes primarias de carácter municipal (principalmente Actas Capitulares). Dado el papel que desempeñan los ayuntamientos en la gestión del riesgo, este tipo de fuentes suponen la mejor aproximación para observar vicisitudes climáticas de manera directa ${ }^{36}$. En este tipo de documentos la información extraíble se centra en las vicisitudes que los agentes atmosféricos y el devenir del clima tenían para la población. De esta manera, los eventos meteorológicos extremos eran siempre tratados de forma exhaustiva.

Los periódicos también suponen una fuente de datos muy valiosa al ofrecer información detallada de todo tipo de vicisitudes ambientales que afectan a la población y sus actividades económicas ${ }^{37}$. Además, los cambios políticos y sociales acaecidos en España a partir del s. XIX, dieron lugar a una enorme inestabilidad institucional que supuso que la documentación oficial perdiera en parte su valor para estudiar el clima. En este sentido, los periódicos son en cierta forma la continuación de este tipo de fuentes, ya que presentan homogeneidad temporal y suelen ser estables en su estructura organizativa.

En resumen, se han consultado los siguientes archivos (Tabla 1):

Tab. 1. Archivos y fuentes consultadas

\begin{tabular}{|l|l|c|}
\hline \multicolumn{1}{|c|}{ Nombre del Archivo: } & \multicolumn{1}{|c|}{ Tipo de Fuente: } & $\%^{*}$ \\
\hline Archivo Municipal de Murcia & $\begin{array}{l}\text { Actas Capitulares; legajos; libros antiguos; } \\
\text { periódicos hasta 1950 }\end{array}$ & 59 \\
\hline $\begin{array}{l}\text { Archivo de la Catedral de } \\
\text { Murcia }\end{array}$ & Actas Capitulares Eclesiásticas & 5 \\
\hline $\begin{array}{l}\text { Archivo Histórico Provincial de } \\
\text { Murcia }\end{array}$ & $\begin{array}{l}\text { Legajos; cartografía; informes de } \\
\text { infraestructuras hídricas }\end{array}$ & 1 \\
\hline Biblioteca Regional de Murcia & Periódicos desde 1950 & 35 \\
\hline
\end{tabular}

${ }^{*}$ La columna \% hace referencia al porcentaje que cada tipo de fuente supone sobre el total de fuentes consultadas.

Fuente: Elaboración propia.

36. METCALFE et al., 10/3 (2002): 11-14.

37. Alberola Romá, 12 (2015). Mas Galvañ, 2016: 179-202.

Revista de Historia Moderna, n. ${ }^{\circ} 35$ (2017) (pp. 308-344) | ISSN-e: 1989-9823 | ISSN: 0212-5862 
En cuanto al modo en que se ha generado la documentación, casi la totalidad de las fuentes consultadas son primarias o directas. Todas las actas, legajos, correspondencia, informes y periódicos son de este tipo ${ }^{38}$. En informes antiguos y recientes, en cuyo relato el autor no era parte implicada (es decir, son obras secundarias o terciarias), la información solo se ha tenido en cuenta como comparadores indirectos. Respecto a las contingencias que ocasiona el fenómeno ambiental documentado los periódicos relatan aspectos físicos, humanos y también biológicos, las actas capitulares se centran en aspectos humanos y en menor medida biológicos, al igual que los legajos ${ }^{39}$.

\section{Metodología}

El Índice de Cambios Perceptuales a los Riesgos Climáticos (ICPRC), a través del análisis documental, pretende analizar la percepción y el impacto de un desastre natural. Para lograr este objetivo se analiza la evolución de cuatro factores claves en los procesos de riesgo: la percepción de los agentes responsables del impacto, la percepción de la peligrosidad, la vulnerabilidad y la estrategia de adaptación y resiliencia.

Antes de aplicar el método es necesario elegir los eventos climáticos extremos a estudiar con algún criterio específico. Aquí, teniendo en cuenta que el periodo de estudio va desde el siglo XVII hasta la actualidad, se elige la sequía y la inundación más catastrófica en cada uno de los siglos estudiados, con una diferencia temporal de al menos 100 años $^{40}$ y concluyendo en el último evento catastrófico en el área de estudio. De este modo, se aplica la metodología a 8 eventos en total, 4 para las sequías y 4 para las inundaciones $^{41}$ (Tabla 2).

38. BARRIENDOS VALLVÉ, 30-31 (1996-1997): 71.

39. BARRIENDOS VALLVÉ, 3 (1999).

40. Esta es una forma de validar el método a través de grandes saltos temporales. En posteriores trabajos se pretende ampliar esta metodología a un número mayor de eventos con mayor proximidad temporal.

41. GIL-GUIRADO, 2013: 523. 
Deconstruyendo riesgos. Cuatro siglos de cambios en la vulnerabilidad y adaptación a las inundaciones y sequías en Murcia

Tab. 2. Eventos extremos analizados

\begin{tabular}{|c|l|c|l|c|}
\hline Periodo & \multicolumn{1}{|c|}{ Inundaciones } & $\begin{array}{l}\text { Documentos } \\
\text { Clasificados }\end{array}$ & \multicolumn{1}{|c|}{ Sequías } & $\begin{array}{l}\text { Documentos } \\
\text { Clasificados }\end{array}$ \\
\hline s. XVII & $\begin{array}{l}\text { 14/10/1651 (Riada de San } \\
\text { Calixto) }\end{array}$ & 119 & $\begin{array}{l}\text { Entre } 1625 \mathrm{y} \\
1632\end{array}$ & 173 \\
\hline s. XVIII & $\begin{array}{l}\text { 06/09/1733 (Riada de } \\
\text { Ntra. Señora de los Reyes) }\end{array}$ & 72 & $\begin{array}{l}\text { Entre } 1747 \mathrm{y} \\
1751\end{array}$ & 94 \\
\hline s. XIX & $\begin{array}{l}15 / 10 / 1879 \text { (Riada de } \\
\text { Santa Teresa) }\end{array}$ & 191 & $\begin{array}{l}\text { Entre } 1846 \mathrm{y} \\
1850\end{array}$ & 154 \\
\hline s. XX-XXI & $\begin{array}{l}28 / 09 / 2012 \text { (Riada de San } \\
\text { Wenceslao) }\end{array}$ & 43 & $\begin{array}{l}\text { Entre } 2004 \mathrm{y} \\
2007\end{array}$ & 846 \\
\hline
\end{tabular}

Fuente: Elaboración propia.

La duración del evento es un aspecto importante, ya que informa tanto del nivel de afección del mismo, como de las estrategias de resiliencia. En este sentido, para el caso de las inundaciones, el evento comienza el día en que se produce la crecida de las aguas y concluye cuando en las fuentes de información disponibles transcurre al menos un mes sin ninguna noticia directa del fenómeno, entendiendo que ya no es un tema de preocupación e interés general que obligue a una atención prioritaria. Por las peculiaridades de las sequías este proceso difiere. El análisis de un evento de sequía comienza cuando la documentación hace referencia explícita a una falta de agua causada por la falta de lluvias y concluye cuando transcurren al menos tres meses sin noticas al respecto (una estación del año).

El método del ICPRC es una derivación del análisis de contenido aplicado a la climatología histórica. El análisis de contenido es una técnica de investigación usada para identificar el sentido y la intencionalidad dados a todo relato escrito, teniendo en cuenta el contexto histórico, social y cultural de cuando se redactó dicho texto ${ }^{42}$. Su uso en el estudio del clima es aún minoritario y relativamente reciente. Moodie y Catchpole ${ }^{43}$ fueron pioneros al analizar con este método los diarios meteorológicos de la Hudson's Bay Company. Los trabajos de Prieto ${ }^{44}$ han impulsado esta técnica, demostrando su validez

42. BARDIN, 1986: 69.

43. MOOdIE y CATCHPOLE, 1975.

44. PRIETO et al., 73/1-2 (2005).

Revista de Historia Moderna, n. ${ }^{\circ} 35$ (2017) (pp. 308-344) | ISSN-e: 1989-9823 | ISSN: 0212-5862 
para los estudios de historia ambiental. Recientemente, la tesis doctoral de Salvador Gil Guirado ${ }^{45}$ validó este método para estudiar el clima histórico y los riesgos naturales en los países iberoamericanos.

De esta forma, el procedimiento del ICPRC se basa en el análisis de todos los textos contemporáneos a la catástrofe estudiada que hacen referencia explícita a su impacto y consecuencias. Los cuatro factores a estudiar se evidencian en los textos escritos a través de distintas expresiones y referencias. Estas expresiones y referencias pueden ser clasificadas dicotómicamente (presencia $=1$, ausencia $=0$ ) en varios indicadores que se refieren a cualquiera de los cuatro factores analizados. Finalmente, se registra el número total de ocurrencias de cada indicador (presencia $=1$ ) y se asigna un valor porcentual dentro del factor al que hace referencia. Un mismo documento puede aludir a indicadores que pertenecen a diferentes factores. En promedio, cada documento clasificado arroja 8,4 indicadores para inundaciones y 7,1 para sequías.

La mayoría de los indicadores han sido usados en otros trabajos y modelos de análisis de la vulnerabilidad ${ }^{46}$, otros son nuevos surgidos de la necesidad de hacer un modelo aplicable en distintos periodos (Ver Anexo: Indicadores usados por el ICPRC).

Para analizar la evolución de los cuatro factores analizados, se suman los puntos de todos los indicadores de un determinado factor y se calcula el porcentaje que supone esta suma en relación a la suma de todos los indicadores.

Se parte de las siguientes hipótesis:

1. Cuanto mayores sean las consideraciones que los actores contemporáneos a la catástrofe hacen acerca del peligro natural, las personas se protegerán mejor ante los riesgos naturales (Factor: Percepción de la peligrosidad $)^{47}$.

2. Cuanto mayores sean las consideraciones sobre el impacto social y territorial del evento, mayor será la vulnerabilidad social y biofísica de dicho evento (Factor: Vulnerabilidad Global).

45. GIL-GUIRADO, op. cit.

46. MESSERLi op. cit. BROOKS, AdGER y KELLy, 15/2 (2005): 151-163. ENDFIELD, 83 (2007): 9-38.

47. DAKE,48/4 (1992): 21-37. 
3. Cuanto mayores sean las consideraciones acerca de las medidas para superar el evento y prepararse para el futuro, mejor será la resiliencia y la adaptación (Factor: Estrategia de adaptación y resiliencia) ${ }^{48}$.

En relación a la percepción de los culpables (Factor: Percepción de los agentes responsables del impacto), partiendo de que el riesgo es una construcción social $^{49}$ consecuencia directa del modelo territorial implementado por cada sociedad, una mayor percepción de que la responsabilidad es humana, supone un avance en la comprensión de los procesos de riesgo, frente a una excesiva culpabilización de los elementos naturales o cuestiones divinas. En total el ICPRC integra 119 indicadores agrupados en cuatro factores (Tabla 3).

Tab. 3. Factores, subfactores y número de indicadores del ICPRC

\begin{tabular}{|c|c|c|c|c|}
\hline \multicolumn{2}{|c|}{ Factor } & $\begin{array}{c}\text { Indicadores } \\
\text { de } \\
\text { inundaciones }\end{array}$ & $\begin{array}{c}\text { Indicadores } \\
\text { de sequías }\end{array}$ & Total \\
\hline \multicolumn{2}{|l|}{$\begin{array}{l}\text { 1. Percepción sobre los agentes } \\
\text { responsables del impacto }\end{array}$} & 26 & 26 & 26 \\
\hline \multicolumn{2}{|l|}{ 2. Percepción de la peligrosidad } & 7 & 6 & 10 \\
\hline \multirow{3}{*}{ 3. Vulnerabilidad Global } & Vulnerabilidad social & 19 & 19 & 19 \\
\hline & Vulnerabilidad biofísica & 19 & 17 & 22 \\
\hline & Subtotal: & 38 & 36 & 41 \\
\hline \multirow{4}{*}{$\begin{array}{l}\text { 4. Estrategia de adaptación y } \\
\text { resiliencia }\end{array}$} & $\begin{array}{l}\text { Medidas no } \\
\text { implementadas }\end{array}$ & 21 & 21 & 21 \\
\hline & Medidas implementadas & 21 & 21 & 21 \\
\hline & Subtotal: & 42 & 42 & 42 \\
\hline & TOTAL: & 113 & 110 & 119 \\
\hline
\end{tabular}

Fuente: Elaboración propia.

\subsection{Factor percepción de los agentes responsables del impacto}

La identificación de los agentes a quienes se les atribuye responsabilidad en el impacto de una catástrofe permite una mejor contextualización del evento ${ }^{50}$. Los indicadores empleados en este factor señalan a los agentes o grupos

48. ENDFIELD, 109/10 (2012): 3676-3681.

49. GARCÍA ACOSTA, op. cit.

50. Ribas Palom y SaURí Pujol, 23-24 (1996): 229-244. 
sociales que de manera contemporánea al evento fueron culpabilizados por sus coetáneos.

Se puede concebir, que este factor informa de la vulnerabilidad ideológica, cultural, educativa y política ${ }^{51}$, y que por lo tanto, informa del contexto sociopolítico durante cada evento.

Se diferencian 26 indicadores, que distinguen todos los actores sociales o elementos a los que se ha culpado de los problemas ocasionados por la catástrofe en los últimos cuatro siglos. Estos indicadores se resumen en cuatro causas generales que diferencian si se culpabiliza a la acción antrópica, a la naturaleza, a la divinidad, o si por el contrario no se señalan culpables específicos (Ver Anexo: Indicadores usados por el ICPRC).

Estos cuatro indicadores son los que mejor informan de la vulnerabilidad cultural y política de cada momento, ya que se parte de la hipótesis de que antes de la irrupción de las corrientes racionalistas y en estados absolutistas, sería muy frecuente la atribución de responsabilidades a entes supra humanos como la naturaleza y la divinidad, mientras que serían escasas las referencias a colectivos humanos concretos y testimoniales las responsabilidades atribuidas a los órganos de poder. Esta situación cambia de manera progresiva con la irrupción de las corrientes ilustradas y la extensión de los conflictos de clase, hasta llegar al momento actual.

\subsection{Factor percepción de la peligrosidad}

Son indicadores referentes a cómo y en qué medida las personas contemporáneas al evento consideraban el papel de los factores naturales como desencadenantes del evento. Esto es de especial importancia porque cuanto mayor y más acertada sea la percepción del peligro natural mejor se protegerá la población durante el desarrollo de una catástrofe ${ }^{52}$. En total se computan 10 variables en este subgrupo, cuatro específicas de las inundaciones y tres de las sequías (Ver Anexo: Indicadores usados por el ICPRC).

51. Wilches-Chaux, op. cit.

52. DAKE, op. cit. 


\subsection{Factor vulnerabilidad global}

La vulnerabilidad global es la suma de los subfactores vulnerabilidad social y vulnerabilidad biofísica ${ }^{53}$.

Según Cutter, Boruff y Shirley ${ }^{54}$ la vulnerabilidad social es en parte el resultado de las desigualdades sociales, en la medida en que los factores sociales influyen en dar forma a la susceptibilidad de los diferentes colectivos sociales y también a dar forma a su capacidad de respuesta. De esta manera, los actores sociales señalados como afectados por las personas contemporáneas a una catástrofe, informan de manera directa de cómo estas desigualdades se plasman en unos mayores impactos a determinados sectores de la población. No todas las noticas sobre un evento informan sobre impactos a actores sociales, por lo tanto una mayor cantidad de información que haga referencia a actores sociales afectados, revela una mayor vulnerabilidad social. El ICPRC, diferencia las personas afectadas por la catástrofe en 19 indicadores distinguiendo el colectivo, clase, minoría, gremio o grupo de edad al que se refieren los documentos contemporáneos al evento. Estos indicadores se resumen en siete tipos de usos del territorio afectados, lo que facilita la comparación a lo largo del tiempo (Ver Anexo: Indicadores usados por el ICPRC).

La vulnerabilidad biofísica hace referencia a las afecciones que el desastre ha originado en el territorio tanto a sus elementos naturales, como antrópicos. Es la plasmación de una exposición que deja en situación de peligro a bienes y personas. Sugiere tanto un componente físico asociado a la naturaleza del riesgo, como un componente biológico o social asociado a las propiedades del sistema que se ven afectadas ${ }^{55}$.

En total se diferencian 22 indicadores que hacen referencia al tipo de daño que se señala explícitamente en los documentos y que las personas contemporáneas a la catástrofe asocian directamente con el impacto del evento. Cuatro de estos indicadores son específicos de las inundaciones y tres de las sequías (Ver Anexo: Indicadores usados por el ICPRC).

53. WilcheS-CHAUX, op. cit.: 22.

54. CutTer, BORUfF y SHIRLEY, op. cit.: 243.

55. BROOKS, 38 (2003): 4. 


\subsection{Factor estrategia de adaptación y resiliencia}

Los indicadores considerados en este factor hacen referencia a las estrategias seguidas para superar la catástrofe y para una mitigación y evasión de la vulnerabilidad, de cara a mejorar la preparación ante posibles nuevas catástrofes ${ }^{56}$, siendo así concebidas por los actores contemporáneos al evento. Se identifican 22 indicadores, diferenciando si estas medidas son solo propuestas (Subfactor: Medidas no implementadas) o por el contrario comienzan a ponerse en práctica (Subfactor: Medidas implementadas). La suma de ambos subfactores supone la estrategia de resiliencia y adaptación. Los indicadores se resumen en seis indicadores generales que hacen referencia al tipo de medidas propuestas o implementadas (Ver Anexo: Indicadores usados por el ICPRC).

\section{Resultados}

\subsection{Cambios en el tiempo de superación de las catástrofes}

En las inundaciones es posible calcular el tiempo necesario para reponerse de la catástrofe, el cual está en función de la intensidad del evento, la exposición, la vulnerabilidad de la sociedad y la estrategia de adaptación vigente.

La falta de medios económicos y técnicos en el siglo XVII y el alto impacto del evento hicieron que hasta no transcurridos unos 490 días tras la inundación, no se diera por superado el evento. En el siglo siguiente, debido a la menor intensidad del impacto y las medidas estructurales puestas en marcha se redujo este periodo hasta los 227 días. Un siglo después, el tiempo de recuperación volvió a aumentar por la mayor exposición y la gran intensidad de la inundación. Finalmente, para las inundaciones recientes, los menores daños respecto a otras inundaciones, unido a la mejora en los medios técnicos y en la gestión de la catástrofe, incidieron en una reducción notable del tiempo necesario para superar el evento. En este contexto, los primeros diez días son fundamentales, las dos semanas y el mes siguiente suponen efemérides del evento en las que por lo general se recuerda a los afectados y se revisa la marcha de la recuperación (Figura 2).

56. FOLKE, op. cit. 
Deconstruyendo riesgos. Cuatro siglos de cambios en la vulnerabilidad y adaptación a las inundaciones y sequías en Murcia

Fig. 2. Número de días necesarios para superar las inundaciones catastróficas

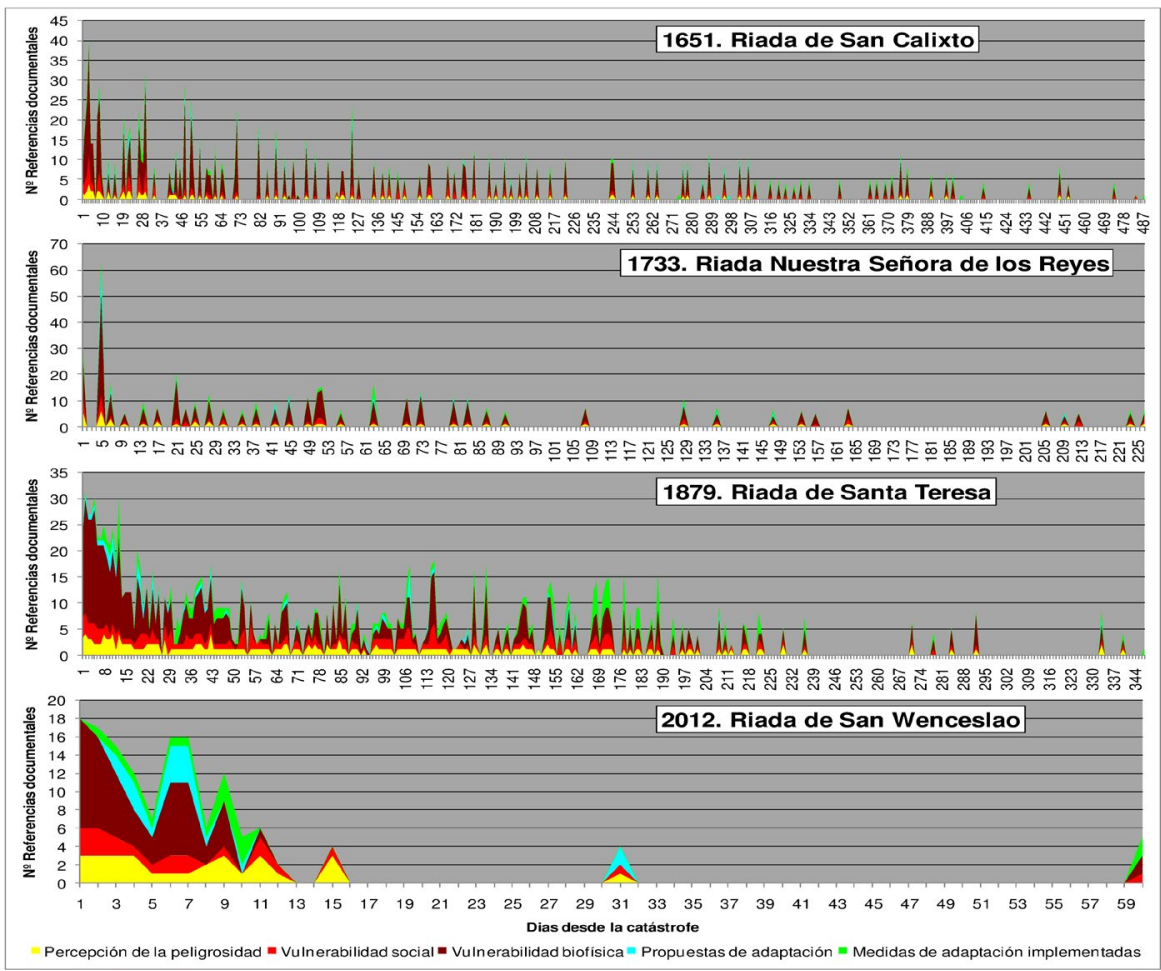

Fuente: Elaboración propia.

La duración de las sequías climáticas es altamente variable, por lo tanto no se puede comparar la duración de este tipo de eventos entre épocas. Sin embargo, es posible observar como las fechas en que se informa de unas mayores afecciones, coinciden con el calendario agrícola y la estacionalidad de las precipitaciones. De esta manera, destaca la gran cantidad de información que se produce durante el verano, por ser el periodo previo a la recolección de los cereales y el de mayor estrés hídrico para las plantas, y durante los equinoccios, por depender la sociedad y el sistema agrícola de las precipitaciones en estas fechas. Sin embargo, esta situación cambia para las sequías 
recientes, motivado esto por la mayor diversidad de la economía local y el uso electoralista de este tipo de eventos. Así, la cobertura mediática para la sequía de 2004 a 2007 sufrió un repunte en el periodo pre y post electoral y se hizo máxima durante el verano por la mayor demanda de agua para uso urbano y por el recrudecimiento de la percepción de la falta de agua (Figura 3).

Fig. 3. Evolución de la distribución mensual de información sobre sequías

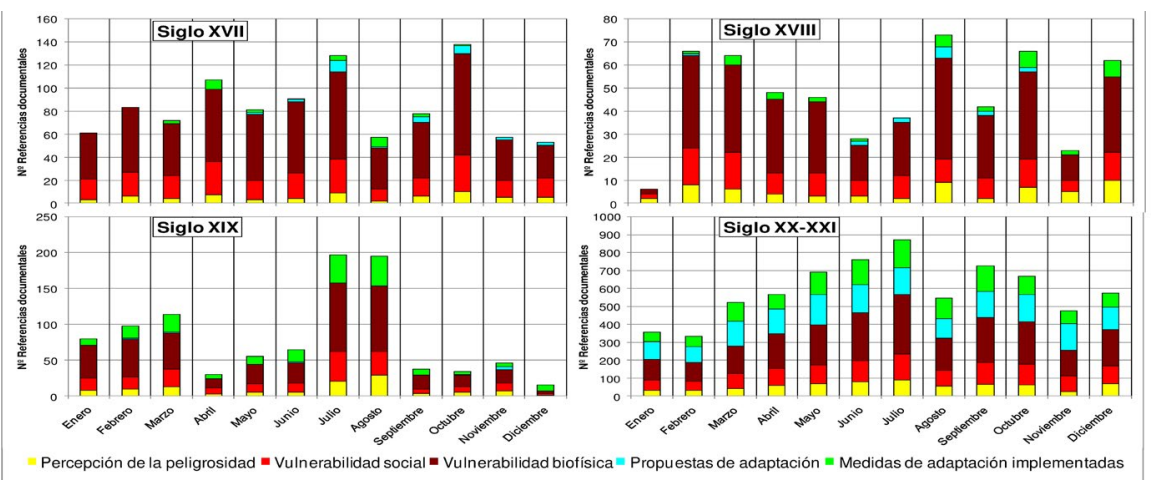

Fuente: Elaboración propia.

\subsection{Cambios en la percepción de los agentes responsables del impacto}

A lo largo de los últimos cuatro siglos se producen importantes cambios perceptuales sobre la responsabilidad en el impacto de las sequías e inundaciones (Figura 3). En relación a las inundaciones, lo más destacable es el aumento del peso de las cuestiones humanas, sobre todo a partir del siglo XIX, algo positivo en la medida en que la sociedad se desprende progresivamente del miedo atávico e irracional a cuestiones religiosas o sobrenaturales. No obstante, todavía siguen siendo muy elevadas las informaciones que culpan a la naturaleza, desviando el foco de atención sobre la deficiente gestión de los gestores territoriales. De esta manera, la percepción de los impactos causados por las inundaciones en Murcia está lejos del paradigma que sitúa al 
ser humano en el epicentro de la responsabilidad en los procesos de riesgo ${ }^{57}$. Algunos titulares de los periódicos murcianos dan cuenta de esta cuestión:

- «La naturaleza no nos perdona $»^{58}$.

- «La naturaleza, tan generosa con la Región de Murcia en muchos aspectos, es cicatera con el agua y cuando el cielo nos la obsequia lo hace en muchas ocasiones con una violencia inmisericorde» ${ }^{59}$.

En cuanto a las sequías, la evolución es parecida a las inundaciones por cuanto se reducen las cargas religiosas en la percepción del riesgo y mejoran notablemente las referencias a la responsabilidad humana. Sin embargo, en la actualidad se ha producido una excesiva politización que hace peligrar la paz social y provoca una verdadera «guerra del agua $»^{60}$ (Figura 4 ).

Fig. 4. Evolución de la percepción causal de las inundaciones y las sequías

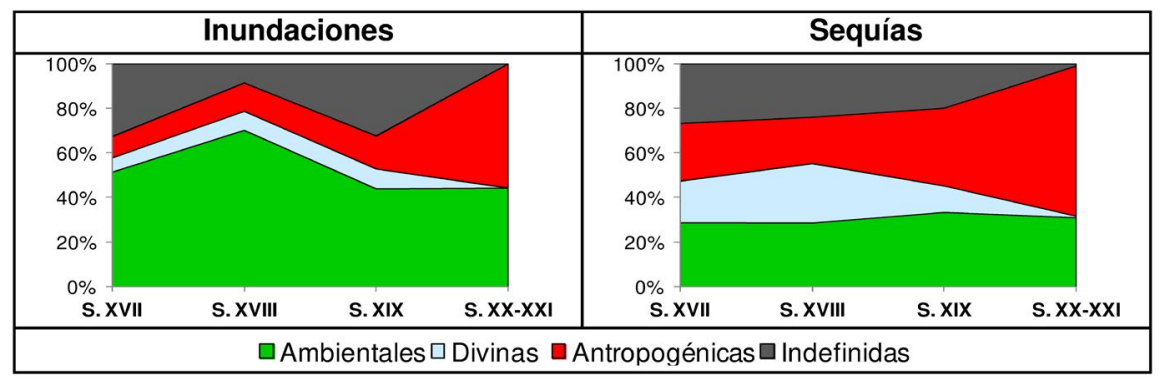

Fuente: Elaboración propia.

Esta problemática se debe en parte a que la puesta en marcha de trasvase Tajo-Segura a finales de los pasados años setenta, vino a complicar aún más la situación, al agregar al sistema hidrológico caudales exógenos que dependen tanto de situaciones climáticas independientes de las de la cuenca del Segura, como de cuestiones políticas ajenas al poder de decisión de los pobladores murcianos. De esta manera, el desarrollo de la sequía gira en torno al

57. BECK, 1992.

58. La Verdad de Murcia (en adelante LVM), 29 de octubre de 2012.

59. LVM, 30 de octubre de 2012.

60. Gil Olcina, 13 (1995b): 21. 
calendario electoral (elecciones generales de marzo de 2004) y a los tensos conflictos territoriales que surgieron entre comunidades autónomas reavivadas por el discurso político pro y anti trasvasista.

Estas condiciones tan particulares hicieron del manejo mediático de la sequía una potente arma política, que en la cuenca del Segura supuso un aumento de la popularidad del gobierno regional bajo el eslogan «Agua para todos», a costa de entrar en conflicto con otras comunidades autónomas vecinas y con el gobierno nacional.

\subsection{Evolución del impacto y la percepción a los eventos climáticos extremos}

La vulnerabilidad global ante las inundaciones en Murcia, a pesar de haber descendido desde el siglo XVII, sigue siendo alta. Al igual que para las sequías, el cambio comienza a producirse a partir del s. XVIII merced a la mejora en las infraestructuras y las propuestas y medidas activas de adaptación, que inciden en una importante reducción de la vulnerabilidad biofísica (Figura 5).

De forma negativa la vulnerabilidad social se incrementa, porque las mejoras en los sistemas de defensa y en el modelo social no han evitado que sigan produciéndose víctimas fatales después de más de cuatro siglos y que los daños afecten a una cantidad creciente de actores sociales. Por otro lado, el aumento de las consideraciones sobre la peligrosidad, denota un mejor conocimiento del entorno y de las condiciones naturales. Estas mejoras han sido posibles gracias a una estrategia de adaptación más proactiva, aunque, han sido especialmente evidentes las propuestas de resiliencia y adaptación y no tanto las medidas puestas en funcionamiento, lo que sin duda ha contribuido a que la vulnerabilidad global y especialmente la social, aun continúen siendo elevadas.

Las diferencias en la duración, área afectada, y sobre todo, en la concentración del impacto en un momento puntual, hacen que el marco ante el riesgo de sequías sea sensiblemente distinto al de las inundaciones y que los impactos se concentren de forma indirecta en los distintos sectores sociales, y no tanto en las infraestructuras territoriales y bienes expuestos (Figura 5).

En referencia a la vulnerabilidad global, las mejoras técnicas han dado lugar a una progresiva reducción desde el siglo XVIII, a causa del aumento de las medidas de adaptación activas basadas en la obra pública. 
La estrategia de adaptación y resiliencia ha mejorado sensiblemente, sin embargo, la mejora viene determinada por el protagonismo creciente de las propuestas y promesas de adaptación, marcadas por un evidente corte electoralista. En cualquier caso, la situación ha mejorado en mayor medida en las sequías que en las inundaciones, donde el descenso en la vulnerabilidad global ha sido menor. Sin embargo, la excesiva politización de las sequías ha propiciado una escasa percepción del peligro.

Fig. 5: Cambios en los factores explicativos del impacto a las inundaciones y sequías

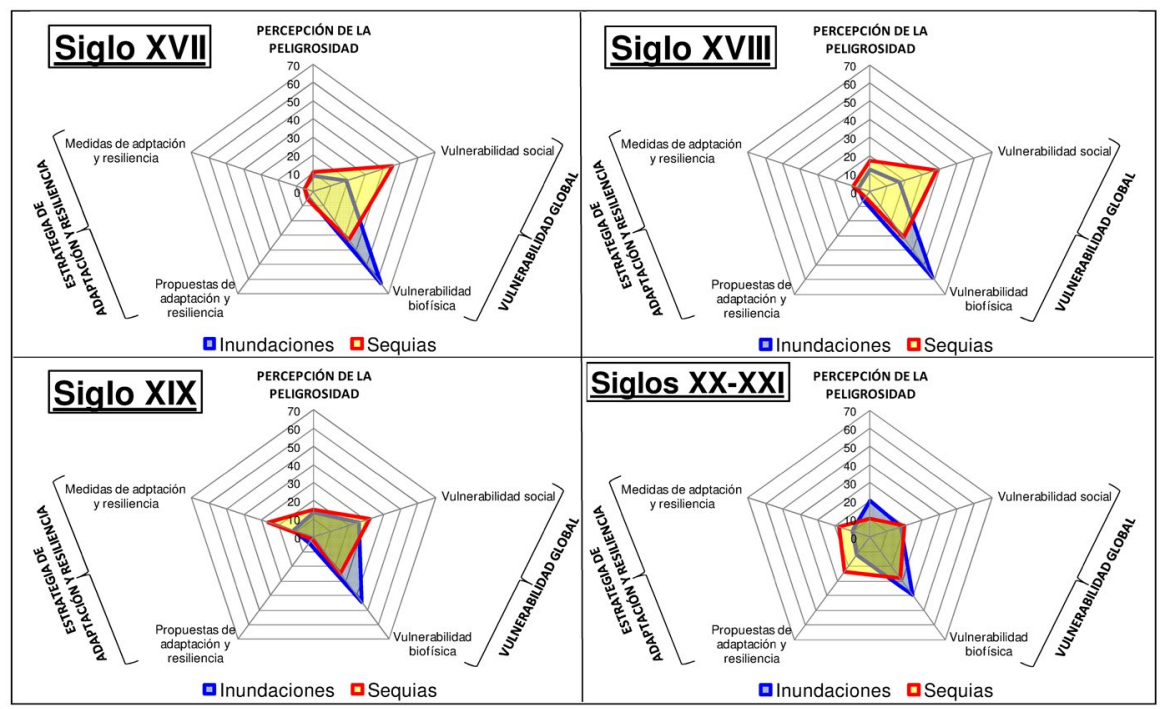

Fuente: Elaboración propia.

\subsection{Cambios en la vulnerabilidad a los eventos climáticos extremos}

Tanto en las inundaciones como en las sequías, los colectivos sociales más vulnerables son los habitantes de la ciudad. En los últimos cuatro siglos, los cambios sociales han hecho que los daños a los religiosos y nobles disminuyan, puesto que tienen un peso testimonial en el conjunto de la sociedad o han desaparecido como colectivo diferenciado (caso de la nobleza). 
En las inundaciones se producen importantes contrastes respecto a las sequías. El impacto a la agricultura y a los servicios públicos disminuye por la mejora en los sistemas de defensa y, en el caso de la agricultura, por la dispersión de las actividades agrícolas por todo el territorio, mientras que el efecto de las inundaciones se concentra en zonas puntuales. Sin embargo, los comerciantes aumentan su vulnerabilidad debido a su mayor exposición dentro de la zona urbana. En las sequías por el contrario, ante situaciones de infradotación de oferta hídrica, la inelasticidad de la demanda doméstica hace que los agricultores sean un sector cada vez más vulnerable (Figura 6).

Una contrapartida de la modernidad es que la falta de agua afecta a nuevos colectivos como comerciantes y turistas. El impacto en el turismo se debe a que en Murcia, el «boom inmobiliario» para residencias turísticas supone una mayor demanda de agua que no puede suplirse durante las sequías. Esto produce una confrontación entre este nuevo uso y el uso agrícola tradicional, viéndose más perjudicado este último.

Fig. 6. Cambios en la vulnerabilidad social

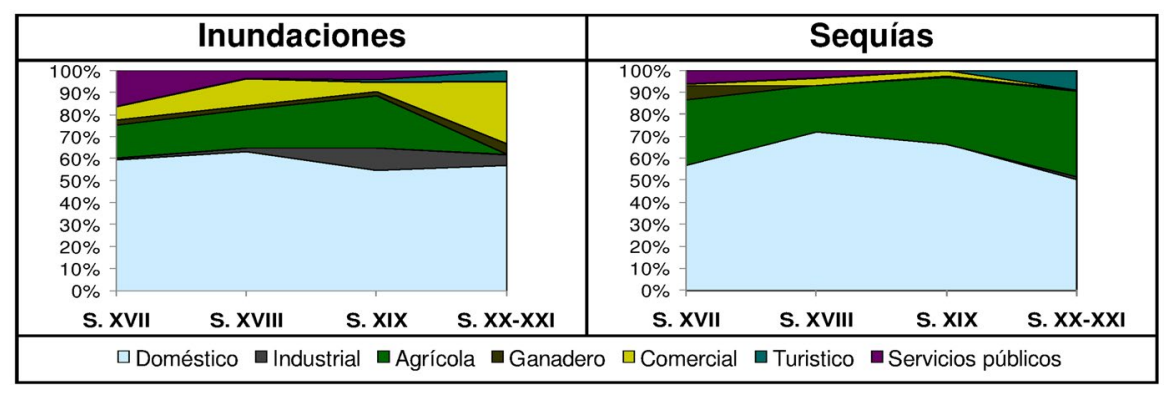

Fuente: Elaboración propia.

La vulnerabilidad biofísica a las inundaciones difiere del caso de las sequías fundamentalmente por el menor peso de las afecciones agropecuarias. Además, se evidencia que la diversificación de la economía a lo largo del periodo de estudio reduce el impacto comparativo al sector agrícola. Al mismo tiempo, el aumento de los bienes expuestos incrementa las afecciones en las comunicaciones y sistemas energéticos (Figura 7).

Las afecciones directas a la sociedad presentan un panorama más complejo y poco halagüeño atendiendo a las posibilidades de mejora a corto plazo. 
Deconstruyendo riesgos. Cuatro siglos de cambios en la vulnerabilidad y adaptación a las inundaciones y sequías en Murcia

Lo más preocupante es que los muertos y heridos tienen una importancia creciente, no en referencia al número de fallecidos, los cuales se reducen, sino en cuanto a la importancia que a estos se atribuye considerando las posibilidades tecnológicas actuales. Esto se debe a que, si bien, es positivo que ante una mayor exposición se haya producido una reducción del número de víctimas fatales, los datos no ocultan que el conjunto de la sociedad adquiera conciencia de que una buena planificación y gestión personal y colectiva de las inundaciones podría haber evitado las desgracias que aún se producen.

De manera similar a la situación en las sequías, en las inundaciones se ha logrado la seguridad alimentaria de forma inequívoca. Otro rasgo destacable es que siempre se ha dependido en exceso del crédito, lo que ha supuesto seculares problemas financieros en situaciones de gastos imprevistos como las riadas. Para las inundaciones una de las contrapartidas de la modernidad es que la mayor exposición junto con la valoración monetaria creciente de todos bienes expuestos, origina unos impactos crecientes en las viviendas, edificios y enseres materiales. Esta mayor presión sobre el territorio tiene también la contrapartida de una mayor conflictividad social y el aumento de las afecciones económicas generales.

Fig. 7. Cambio en la vulnerabilidad biofísica

\begin{tabular}{|c|c|}
\hline Inundaciones & Sequias \\
\hline $100 \%$ & $100 \%$ \\
\hline $90 \%$ & $90 \%$ \\
\hline $80 \%$ & $80 \%$ \\
\hline $70 \%$ & $70 \%$ \\
\hline $60 \%$ & $60 \%$ \\
\hline $\begin{array}{l}50 \% \\
40 \%\end{array}$ & $\begin{array}{l}50 \% \\
40 \%\end{array}$ \\
\hline $30 \%$ & $30 \%$ \\
\hline $20 \%$ & $20 \%$ \\
\hline & $10 \%$ \\
\hline S. XX-XXI & S. XX-XXI \\
\hline 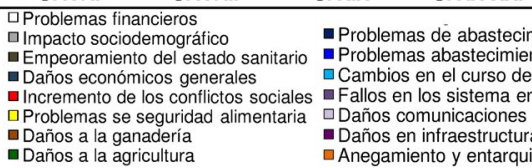 & 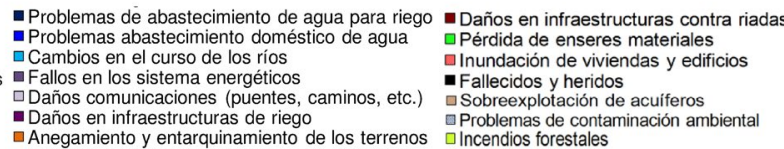 \\
\hline
\end{tabular}

Fuente: Elaboración propia. 
La vulnerabilidad biofísica a las sequías, presenta una composición similar a las inundaciones aunque con importantes diferencias evolutivas (Figura 7). En relación a los impactos de plasmación directa, lo más destacable es que la seguridad alimentaria se ha cubierto totalmente.

Los problemas agropecuarios han sido y siguen siendo una de las principales afecciones territoriales de las sequías, aunque se reducen por los daños crecientes a otros sectores. La mayor demanda ante un recurso limitado, produce problemas en la oferta de agua, aumentando los problemas de abastecimiento de agua, sobre todo para riego. De esta manera, la agricultura padece la inelasticidad de la demanda de agua para uso doméstico.

Esta compleja situación surgida de una mayor presión en el territorio y unas mayores demandas ante un recurso escaso, da lugar a un peligroso aumento de la conflictividad social. A esta situación ha contribuido además el uso partidista que aquí se ha hecho de las sequías, lo cual es muy evidente durante el evento de 2004 a 2007.

Es destacable que la modernidad y el aumento de la capacidad de carga sobre el territorio que posibilita la aplicación de tecnología, presentan algunas contrapartidas en la gestión de las sequías, produciendo un incremento de los problemas medioambientales y la sobreexplotación de recursos hídricos. Estos problemas han aumentado mucho desde el siglo XIX. De este modo, si en el pasado, la ruptura del equilibrio en la relación hombre-naturaleza la sufrían las sociedades, ahora es la naturaleza la que pasa a absorber parte de este impacto.

Sin embargo, la sociedad murciana también es víctima de las contrapartidas de la modernidad, ya que el uso partidista de la escasez de agua evidencia una creciente vulnerabilidad política, a la vez que cobran importancia los problemas financieros y las afecciones económicas generales.

\subsection{Cambios en la estrategia de adaptación y resiliencia: lecciones del pasado}

La estrategia de adaptación y resiliencia revela los cambios en el paradigma de adaptación del ser humano al espacio geográfico que ocupa. De nuevo las diferencias entre la necesaria gestión urgente de las inundaciones, frente a dilatación y dilución temporal de los impactos de las sequías, hace que se produzcan notables diferencias. Lo más destacable es que las sequías posibilitan 
que los poderes económicos y políticos usen su gestión para buscar el favor político, por lo que la estrategia seguida en las propuestas no se materializa en medidas efectivas, como sí ocurre en las inundaciones (Figura 8).

Es destacable que en las inundaciones no ha cambiado el paradigma ilustrado cartesiano que concibe que el ser humano tenga que apropiarse del territorio que ocupa, puesto que siempre han dominado las medidas y propuestas para reducir la vulnerabilidad biofísica a través de obras de ingeniería de alto impacto territorial. No obstante, el alto grado de intervención en el territorio alcanzado ya a finales del siglo XIX en Murcia, junto con la diversificación económica y el aumento de los bienes expuestos, hace que las medidas actuales se centren en ayudar a los sectores económicos afectados. Un aspecto positivo es que las propuestas que abogan por una reducción de la exposición como la mejor herramienta para mitigar el impacto de las inundaciones, empiezan a cobrar importancia, anticipando un previsible y progresivo cambio de paradigma hacia posturas a favor de un mayor equilibrio con el medio.

En las sequías el paradigma intervencionista es mucho más acusado, y lo que es más preocupante, las propuestas van encaminadas en esta línea, lo que dificulta un cambio que fomente una adecuación de la demanda de agua a la oferta. No obstante, las medidas que se están poniendo en marcha son acertadas, puesto que están creciendo las medidas de evasión del peligro, de reducción de la vulnerabilidad social y de reducción de la exposición.

Fig. 8: Cambios en la estrategia de adaptación y resiliencia

\begin{tabular}{|c|c|c|c|c|}
\hline & \multicolumn{2}{|c|}{ Inundaciones } & \multicolumn{2}{|c|}{ Sequías } \\
\hline & $\begin{array}{l}\text { Propuestas de } \\
\text { superación }\end{array}$ & $\begin{array}{l}\text { Medidas de } \\
\text { superación }\end{array}$ & $\begin{array}{l}\text { Propuestas de } \\
\text { superación }\end{array}$ & $\begin{array}{l}\text { Medidas de } \\
\text { superación }\end{array}$ \\
\hline \multicolumn{5}{|l|}{ s. $x x-x x I$} \\
\hline \multicolumn{5}{|l|}{ s. XIX } \\
\hline \multicolumn{5}{|l|}{ s. XVIII } \\
\hline \multicolumn{5}{|l|}{ s. xvII } \\
\hline \multicolumn{5}{|c|}{$0 \% 20 \% 40 \% 60 \% 80 \% 100 \% \quad 0 \% 20 \% 40 \% 60 \% 80 \% 100 \%$} \\
\hline \multicolumn{5}{|c|}{ 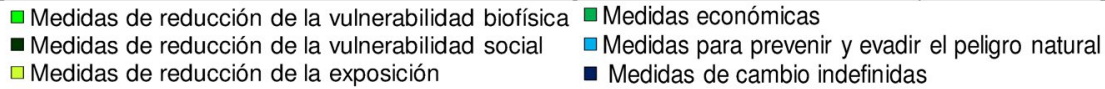 } \\
\hline
\end{tabular}

Fuente: Elaboración propia. 


\section{Discusión y conclusiones}

Siguiendo el trabajo de Messerli et al., ${ }^{61}$ observamos diferentes «trayectorias de vulnerabilidad» en Murcia desde el siglo XVII hasta la actualidad. En concreto se observan tres fases diferenciales en la relación ser humano-naturaleza:

1. Sociedades agrarias preindustriales entre el siglo XVII y mediados del XVIII, donde la sociedad mostraba pasividad ante las vicisitudes ambientales, apoyada en la falta de medios técnicos y en el gran peso de la religión

2. Sociedades agrarias industriales entre mediados del siglo XIX y mediados del siglo $\mathrm{XX}$, donde en sociedades eminentemente agrarias y con una fuerte, pero descendente, carga religiosa, las ideas ilustradas y los avances tecnológicos, permiten hacer intervenciones fuertes en el medio para defenderse del peligro

3. Sociedades modernas actuales, a partir de la segunda mitad del siglo $\mathrm{XX}$, cuando la economía se diversifica y se globalizan los problemas y ventajas de la economía globalizada. A partir de este momento se produce un aumento exponencial de la exposición a los peligros naturales, ante lo cual aumentan las medidas de protección.

No obstante, la aplicación del ICPRC permite vislumbrar una cuarta fase, muy incipiente y teórica aún, en la que las medidas de adaptación pasan a considerar la evasión del peligro como la mejor defensa ante la amenaza de las catástrofes naturales.

En las sequías, a pesar de los cambios sociales y tecnológicos que se han producido en los últimos cuatro siglos, el marco general no ha cambiado excesivamente y aunque se producen notables avances, siguen persistiendo viejas costumbres. La gestión reciente de las sequías evidencia una creciente vulnerabilidad política, mostrando un espacio escasamente adaptado a su realidad ambiental. Esta situación tiene una difícil solución, porque a lo largo del periodo de estudio ha sido una constante el hecho de que los grupos de poder apoyen parte de su discurso en una asociación entre el modelo de crecimiento y el aumento de la cantidad de agua disponible. Esta manipulación

61. MESSERLi et al., op. cit.: 459.

Revista de Historia Moderna, n. 35 (2017) (pp. 308-344) | ISSN-e: 1989-9823 | ISSN: 0212-5862 
para buscar el favor popular, lejos de reducirse, va en aumento. Selznick ${ }^{62}$, ya señaló hace más de medio siglo que la vulnerabilidad de las instituciones a la manipulación política aumenta a medida que la sociedad se vuelve cada vez más una sociedad de masas y se asocia con el debilitamiento de las élites creativas y culturales. Por lo tanto, es necesario mejorar los canales de comunicación para implicar al conjunto de la sociedad de forma activa en la gestión y prevención de los desastres, anteponiendo el interés general al particular ${ }^{63}$.

Esta situación es una constante en el discurso hídrico de los diversos territorios estatales, donde los grupos de poder siempre han tratado de atribuir distinto simbolismo al agua (sentido de nación, religioso, patriótico, etc.), pero siempre son escasos los mensajes de sostenibilidad en la explotación del recurso ${ }^{64}$. A este respecto, es posible definir otro nuevo tipo de sequía, la «sequía política», que es aquella producida cuando a pesar de no existir unos condicionantes ambientales e hidrológicos detonantes, las decisiones políticas repercuten en que se produzca la percepción de una falta de agua que acaba afectando al sistema socioeconómico.

En el caso de las inundaciones, la percepción sobre los mecanismos físicos que las ocasionan es una constante en aumento a lo largo de todo el periodo estudiado. Sin embargo, a la hora de afrontar el evento, los gestores del territorio y los pobladores se encuentran con una burocracia y pobreza económica que ralentiza la resolución de los problemas. Este hecho se erige como otro factor de vulnerabilidad secular y lejos de mitigarse, aumenta.

Otro hecho destacable y preocupante, es que se produce siempre un desfase en la planificación entre la zona vulnerable y la zona de prioridad de defensa. Así, desde que el hombre posee capacidad para regular los cauces de los ríos, en los casos en que se han tomado soluciones, siempre ha sido por medio de obra dura y exclusivamente en las áreas donde alguna catástrofe hizo demasiado evidentes los problemas y riesgos asociados al peligro. Esta falta de previsión y planificación ha dado lugar a soluciones parciales en las áreas previamente afectadas, pero se han creado nuevos espacios de riesgo ${ }^{65}$, donde

62. SELZNICK, 56/4 (1951): 320-331.

63. SAURÍ et al., op. cit.: 277.

64. TÀbara, COSTEjÀ y VAN WOERDEN, 73 (2004): 175.

65. Calvo García-Tornel, op. cit. 
la experiencia hace prever que no será hasta una nueva catástrofe cuando se tomarán las medidas oportunas.

En las inundaciones recientes se puede afirmar, que el principal problema es una falta de planificación adecuada que ha propiciado un aumento de la exposición a las zonas en riesgo, sin que se hayan llevado a cabo las obras de seguridad necesarias. Esto ya ha sido esbozado por McMichael ${ }^{66}$ al hablar de que las sociedades actuales, a pesar de tener una tecnología más efectiva para la protección y para la producción de recursos, son más vulnerables por la mayor presión sociodemográfica y la menor flexibilidad en sus estructuras.

En resumen, a pesar de las notables mejoras en la estrategia de adaptación durante los último cuatro siglos, no se ha alcanzado una gestión adaptativa de los riesgos naturales en Murcia. Por lo tanto, queda pendiente para la sociedad murciana la implementación de un modelo de interacción socioambiental basado en la evasión del riesgo y en el respeto a los valores naturales.

\section{Bibliografía}

ADGER, W. Neil, et al., «Social-ecological resilience to coastal disasters», Science, 309/5737 (2005): 1036-1039. http://dx.doi.org/10.1126/science.1112122

Alberola RomÁ, Armando, «Clima, crisis y reformismo agrario en tiempos del conde de Floridablanca», Mélanges de la Casa de Velázquez, 39/2 (2009): 105-125. Disponible en: https://mcv.revues.org/2845

Alberola Romá, Armando, «Tiempo, clima y enfermedad en la prensa española de la segunda mitad del siglo XVIII. Diarios meteorológicos y crónicas de desastres en el Memorial Literario», El Argonauta español, 12 (2015). http:// dx.doi.org/10.4000/argonauta.2142

Alberola Romá, Armando y Olcina Cantos, Jorge, Desastre natural, vida cotidiana y religiosidad popular en la España moderna y contemporánea, Alicante, Universidad de Alicante, 2009.

BARDín, Laurence, Análisis de Contenido, Madrid, Akal, 1986.

BARREDO, José I., «Normalised flood losses in Europe: 1970-2006», Natural Hazards and Earth System Science, 9 (2009): 97-104. Disponible en: https:// www.nat-hazards-earth-syst-sci.net/9/97/2009/nhess-9-97-2009.pdf

66. MCMICHAEL op. cit.: 4730. 
Deconstruyendo riesgos. Cuatro siglos de cambios en la vulnerabilidad y adaptación a las inundaciones y sequías en Murcia

BARRIENDOS VALlVÉ, Mariano, «El clima histórico de Catalunya (siglos XIV-XIX). Fuentes, métodos y primeros resultados», Revista de Geografía, 30-31 (19961997): 69-96. Disponible en: http://www.raco.cat/index.php/RevistaGeografia/ article/viewFile/46096/56902

BARRIENDOS VALLVÉ, Mariano, «La climatología histórica en el marco geográfico de la antigua Monarquía Hispana», Scripta Nova. Revista electrónica de geografía y ciencias sociales, 3 (1999) Disponible en: http://www.ub.edu/geocrit/ sn-53.htm [consultado el 7 de abril de2014]

BECK, Ulrich, Risk society: Towards a new modernity, Londres, Sage Publications, 1992.

BIRKMANN Jörn (ed.), Measuring Vulnerability to Natural Hazards: Towards Disaster Resilient Societies. Tokyo, United Nations Univ Press, 2007.

BRAUDEL, Fernand, Civilización material, economía y capitalismo, siglos XV-XVIII, Barcelona, Alianza Editorial, 1984.

BROOKS, Nick, «Vulnerability, risk and adaptation: A conceptual framework», Tyndall Centre for Climate Change Research Working Paper, 38 (2003): 1-16. Disponible en: https://adapt.nd.edu/resources/1734

BroOKs, Nick, ADGER, W. Neil \& Kelly, P. Mick, «The determinants of vulnerability and adaptive capacity at the national level and the implications for adaptation», Global Environmental Change, 15/2 (2005):151-163. https://doi. org/10.1016/j.gloenvcha.2004.12.006

CALVO GARCíA-TORnel, Francisco, Sociedades y territorios en riesgo, Barcelona: Ediciones del Serbal, 2001.

CARDONA Omar-Darío et al., «Determinants of risk: exposure and vulnerability», en Christopher B. Field et al. (eds), Managing the risks of extreme events and disasters to advance climate change adaptation, Cambridge/New York, Cambridge University Press, 2012: 65-108, 2012. Disponible en: https://www. ipcc.ch/pdf/special-reports/srex/SREX-Chap2_FINAL.pdf

CREM: Centro Regional de Estadística de Murcia. Centro Regional de Estadística de Murcia: http://econet.carm.es/web/crem/inicio/-/crem/sicrem/PU_datosBasicos/secl64.html [Consultado el 10 de diciembre de 2016]

Cutter, Susan L, BorufF, Bryan J. \& SHIRley, W. Lynn, «Social Vulnerability to Environmental Hazards», Social Science Quarterly, 84/2 (2003): 242-261. http://dx.doi.org/10.1111/1540-6237.8402002

DAKE, Karl, «Myths of nature: Culture and the social construction of risk», Journal of Social Issues, 48/4 (1992): 21-37. http://dx.doi.org/10.1111/j.1540-4560.1992. tb01943.x 
ENDFIELD, Georgina H., «Archival explorations of climate variability and social vulnerability in colonial Mexico», Climatic Change, 83 (2007): 9-38. https:// doi.org/10.1007/s10584-006-9125-3

ENDFIELD, Georgina H., «The resilience and adaptive capacity of social-environmental systems in colonial Mexico», Proceedings of the National Academy of Sciences of the United States of America, 109/10 (2012): 3676-3681. http:// dx.doi.org/10.1073/pnas.1114831109

FIELD Christopher B. et al. (eds.), Managing the Risks of Extreme Events and Disasters to Advance Climate Change Adaptation. A Special Report of Working Groups I and II of the Intergovernmental Panel on Climate Change, Cambridge/ New York, Cambridge University Press, 2012. Disponible en: https://www. ipcc.ch/pdf/special-reports/srex/SREX_Full_Report.pdf

FOLKE, Carl, «Resilience: The emergence of a perspective for social-ecological systems analyses», Global environmental change, 16/3 (2006): 253-267. https://doi.org/10.1016/j.gloenvcha.2006.04.002

GARCíA ACOSTA, Virginia, «El riesgo como construcción social y la construcción social de riesgos», Desacatos: Revista de Antropología Social, 19 (2005): 1-24. Disponible en: http://desacatos.ciesas.edu.mx/index.php/Desacatos/article/ view/1042/890

GEIGER, Folkwin, «El sudeste Español y los problemas de aridez», Revista de Geografía, 7/1-2 (1973): 166-209. Disponible en: http://www.raco.cat/index. php/RevistaGeografia/article/view/45876/60295

Gil Olcina, Antonio, «Rasgos específicos del Sureste Peninsular», Paralelo 37: Revista de Estudios Geográficos, 17 (1995a): 69-79.

Gil OlcinA, Antonio, «Conflictos autonómicos sobre trasvases de agua en España», Investigaciones geográficas, 13 (1995b): 17-28. http://dx.doi. org/10.14198/INGEO1995.13.05

GIL-GUIRADO, Salvador, Reconstrucción climática histórica y análisis evolutivo de la vulnerabilidad y adaptación a las sequías e inundaciones en la Cuenca del Segura (España) y en la Cuenca del Río Mendoza (Argentina). Tesis doctoral dirigida por José María Gómez Espín y María del Rosario Prieto, Murcia, Universidad de Murcia, 2013. Disponible en: https://digitum.um.es/xmlui/ handle/10201/36964

GIL-GuIRADO, Salvador, EsPín SÁnCHEZ, José Antonio y PRIETO, $\mathrm{M}^{\mathrm{a}}$ del Rosario, «Can we learn from the past? Four hundred years of changes in adaptation to floods and droughts. Measuring the vulnerability in two Hispanic 
cities», Climatic Change, 139/2 (2016): 183-200. https://doi.org/10.1007/ s10584-016-1768-0

GÓMEZ BAGGETHUN, Erik et al., «Traditional ecological knowledge and community resilience to environmental extremes: A case study in Doñana, SW Spain», Global Environmental Change, 22/3 (2012): 640-650. https://doi. org/10.1016/j.gloenvcha.2012.02.005

HIRABAYASHI, Yukiko et al., «Global projections of changing risks of floods and droughts in a changing climate», Hydrological Sciences Journal, 53/4 (2008): 754-772. http://dx.doi.org/10.1623/hysj.53.4.754

HSIANG, Solomon M. y BURKE, Marshall, «Climate, conflict, and social stability: what does the evidence say? », Climatic Change, 123/1 (2014): 39-55. https:// doi.org/10.1007/s10584-013-0868-3

MÄchtle, B., \& EITEL, B. «Fragile landscapes, fragile civilizations-how climate determined societies in the pre-Columbian south Peruvian Andes», Catena, 103 (2013): 62-73. https://doi.org/10.1016/j.catena.2012.01.012

MAS GALVAÑ, Cayetano, "Clima y meteorología en la prensa provincial española del reinado de Carlos IV (1792-1808)», en Luis A. Arrioja y Armando Alberola (eds.), Clima, desastres y convulsiones sociales en España e Hispanoamérica, siglos XVII-XX, Alicante, Universidad de Alicante/ El Colegio de Michoacán, 2016: 179-202.

MCMichaEL, Anthony J., «Insights from past millennia into climatic impacts on human health and survival», Proceedings of the National Academy of Sciences of the United States of America, 109/13 (2012): 4730-4737. http://dx.doi. org/10.1073/pnas.1120177109

MECD, Ministerio de Educación Cultura y Deporte, Cartografía de la Guerra de la Independencia, http://www.bne.es/es/Micrositios/Guias/Guerra_independencia/recursos_informacion/cartografia, [Consultado el 7 de octubre de 2011]

MESSERLi, Bruno et al., «From nature-dominated to human-dominated environmental changes», Quaternary Science Reviews, 19/1-5 (2000): 459-479. https://doi.org/10.1016/S0277-3791(99)00075-X

Metcalfe, Sarah et al., «The Potential of Archival Sources for Reconstructing Climate and Climate-Related Processes in Latin America» Pages News, 10/3 (2002): 11-14. Disponible en: http://www.pages-igbp.org/download/docs/ newsletter/2002-3/science_highlights/Metcalfe_etal_2002-3(11-14).pdf 
Min, Seung-Ki et al., "Human contribution to more-intense precipitation extremes», Nature, 470/7334 (2011): 378-381. http://dx.doi.org/10.1038/ nature 09763

Moodie, D. W. \& CatChPole, A. J., Environmental Data from Historical Documents by Content Analysis: Frezze-Up and Break-Up of Estuaries on Hudson Bay 17141871. Winnipeg, University of Manitoba,1975.

O'BriEn, Michael J. \& Holland, Thomas D., «The role of adaptation in archaeological explanation», American Antiquity, 57/1 (1992):36-69. https://doi. org/10.2307/2694834

OlCina CANTOS, Jorge, «Cambios en la consideración territorial, conceptual y de método de los riesgos naturales», Scripta Nova. Revista Electrónica de Geografía y Ciencias Sociales. 12/270 (2008). Disponible en: <http://www. ub.es/geocrit/sn/sn-270/sn-270-24.htm> [Consultado el 7 de julio de 2012]

Pérez Morales, Alfredo, Gil-Guirado, Salvador y Olcina Cantos, Jorge, «Housing bubbles and the increase of flood exposure. Failures in flood risk management on the Spanish south-eastern coast (1975-2013)», Journal of Flood Risk Management, 2015. http://dx.doi.org/10.1111/jfr3.12207

PÉrez PiCAzo, Ma Teresa, Lemeunier, Guy y Chacón Jiménez, Francisco, Materiales para una historia de Murcia en los tiempos modernos. Murcia, Universidad de Murcia, 1980.

PRIETO, M. R., et al., «Deriving wind force terms from nautical reports through content analysis. The Spanish and French cases», Climatic Change, 73/1-2 (2005): 37-55. https://doi.org/10.1007/s10584-005-6956-2

Prudhomme, Christel et al., «Hydrological droughts in the 21st century, hotspots and uncertainties from a global multimodel ensemble experiment», Proceedings of the National Academy of Sciences of the United States of America, 111/9 (2014): 3262-3267. http://dx.doi.org/10.1073/pnas.1222473110

RiBAS PAlOM, Anna y SAURí PUJOL, David, «El estudio de las inundaciones históricas desde un enfoque contextual: una aplicación a la ciudad de Girona», Papeles de geografía, 23-24 (1996): 229-244. Disponible en: http://revistas. um.es/geografia/article/view/45191

Ribas PAlOM, Anna y SAURí PujOl, David, «De la geografía de los riesgos a las geografías de la vulnerabilidad», en Joan Nogué y Joan Romero (eds.), Las otras geografías, Valencia, Tirant lo Blanch, 2006: 285-300. 
Deconstruyendo riesgos. Cuatro siglos de cambios en la vulnerabilidad y adaptación a las inundaciones y sequías en Murcia

SAURí PujOL, David, «Tendencias recientes en el análisis geográfico de los riesgos ambientales», Áreas. Revista Internacional de Ciencias Sociales, 23 (2003): 17-30. Disponible en: http://revistas.um.es/areas/article/view/117861

SAURí PUjOL, David, et al., «La percepción del riesgo de inundación: experiencias de aprendizaje en la Costa Brava», Papeles de Geografía, 51-52 (2010): 269-278. Disponible en: http://revistas.um.es/geografia/article/view/114571 SCHIERMEIER, Quirin, «Increased flood risk linked to global warming», Nature, 470/7334 (2011): 316. http://dx.doi.org/10.1038/470316a

SELZNICK, Philip, «Institutional vulnerability in mass society», American Journal of Sociology, 56/4 (1951): 320-331. Disponible en: http://www.jstor.org/ stable/2771695

SERrano MARTíneZ, José Ma y GonZÁlez OrTIZ, José Luis, «El área Metropolitana de Murcia», en VV.AA, Atlas Global de la Región de Murcia, Cap. IV. La organización del territorio: las comarcas. Murcia, Comunidad de Murcia et al., 2007.: 490-499.

SMIT, Barry \& WANDEL, Johanna, «Adaptation, adaptive capacity and vulnerability», Global environmental change, 16/3 (2006): 282-292. https://doi. org/10.1016/j.gloenvcha.2006.03.008

SÖNMEZ, F. Kemal, et al., «An analysis of spatial and temporal dimension of drought vulnerability in Turkey using the standardized precipitation index», Natural Hazards, 35/2 (2005): 243-264. https://doi.org/10.1007/s11069-004-5704-7

TÀBARA, Joan D., COSTEJÀ, Meritxell y VAN WOERDEN, Fincent, «Las culturas del agua en la prensa española. Los marcos culturales en la comunicación sobre el Plan Hidrológico Nacional». Papers, Revista de Sociologia, 73 (2004): 155181. http://dx.doi.org/10.5565/rev/papers/v73n0.1112

TAPSELL, S. M., et al., "Vulnerability to flooding: health and social dimensions», Philosophical Transactions of the Royal Society of London. Series A: Mathematical, Physical and Engineering Sciences, 360/1796 (2002): 15111525. https://doi.org/10.1098/rsta.2002.1013

WILCHES-CHAUX, Gustavo, «La vulnerabilidad global», en Andrew Maskrey (ed.), Los desastres no son naturales. Bogotá: La Red de Estudios Sociales, 1993: 9-50. Disponible en: http://www.desenredando.org/public/libros/1993/

Wilhite, Donald \& GLANTZ, Michael H., «Understanding the drought phenomenon: the role of definitions», Water International, 10/3 (1985): 111-120. http://dx.doi.org/10.1080/02508068508686328

WMO, Report on drought and countries affected by drought during 1974-1985. Geneva, World Meteorological Organization, 1986. 
Deconstruyendo riesgos. Cuatro siglos de cambios en la vulnerabilidad y adaptación a las inundaciones y sequías en Murcia

\section{Anexo: Indicadores usados por el ICPRC}

\begin{tabular}{|c|c|c|c|c|c|c|c|}
\hline \multicolumn{8}{|c|}{ Indicadores para el factor percepción de los responsables } \\
\hline \multicolumn{2}{|r|}{$\begin{array}{c}\text { CAUSAS } \\
\text { GENERALES }\end{array}$} & \multicolumn{6}{|c|}{ AGENTES CULPABILIZADOS } \\
\hline 1 & Ambientales & 1 & \multicolumn{5}{|l|}{ Naturaleza } \\
\hline 2 & Divinas & 2 & \multicolumn{5}{|l|}{ Divinidad } \\
\hline \multirow{12}{*}{\multicolumn{2}{|c|}{ Antropogénicas }} & 3 & \multicolumn{3}{|l|}{ Población rural } & 15 & Terratenientes o propietarios de la tierra \\
\hline & & 4 & \multicolumn{3}{|l|}{ Población urbana } & 16 & $\begin{array}{l}\text { Especuladores e intereses económicos } \\
\text { privados }\end{array}$ \\
\hline & & 5 & \multicolumn{3}{|l|}{ Técnicos } & 17 & Pobres (sectores desfavorecidos) \\
\hline & & 6 & \multicolumn{3}{|l|}{ Gestores del territorio } & 18 & Ricos \\
\hline & & 7 & \multicolumn{3}{|c|}{$\begin{array}{l}\text { Deficiencias en sistema de } \\
\text { abastecimiento o defensa }\end{array}$} & 19 & Extranjeros o personas foráneas \\
\hline & & 8 & \multicolumn{3}{|c|}{$\begin{array}{l}\text { Autoridades competentes en materia } \\
\text { hídrica }\end{array}$} & 20 & Nobles \\
\hline & & 9 & \multicolumn{3}{|c|}{ Inspectores y fuerzas del orden } & 21 & Religiosos \\
\hline & & 10 & \multicolumn{3}{|c|}{ Pequeños propietarios de la tierra } & 22 & Gobierno Nacional \\
\hline & & 11 & \multicolumn{3}{|l|}{ Agricultores } & 23 & Gobierno provincial \\
\hline & & 12 & \multicolumn{3}{|l|}{ Ganaderos } & 24 & Gobierno local \\
\hline & & 13 & \multicolumn{3}{|l|}{ Comerciantes } & 25 & Políticos sin distinción \\
\hline & & 14 & \multicolumn{3}{|c|}{ Trabajadores y propietarios industriales } & & \\
\hline 4 & Indefinidas & 26 & \multicolumn{5}{|l|}{ Sin especificar } \\
\hline \multicolumn{8}{|c|}{ Indicadores para el factor percepción de la peligrosidad } \\
\hline 1 & Lluvias torrenciales* & & & 6 & Falta de & uvias" & \\
\hline 2 & Mat. Arrastrados* & & & 7 & Bajo ni & 1 de rí & s, canales y embalses** \\
\hline 3 & \begin{tabular}{|l|} 
Granizo** \\
\end{tabular} & & & 8 & Orograf & y pen & diente \\
\hline 4 & Alto nivel de ríos y c & canale & & 9 & Natural & a de lo & s materiales \\
\hline 5 & Falta de Nieves en ca & abece & $\mathrm{a}^{* *}$ & & Vegetac & & \\
\hline & & Indi & cadores para el su & facto & pr vulr & rabi & lidad social \\
\hline & SO AFECTADO & & & ACTO & $\mathrm{R} \mathrm{SOC}$ & $\mathrm{L} \mathrm{AF}$ & ECTADO \\
\hline & & 1 & Sin distinción (poblaci & en gen & neral) & 6 & Ricos \\
\hline & & 2 & Niños & & & 7 & Extranjeros o personas foráneas \\
\hline 1 & Doméstico & 3 & Ancianos & & & 8 & Nobles \\
\hline & & 4 & Mujeres & & & 9 & Población Rural \\
\hline & & 5 & Pobres (sectores desfar & recidos & & 10 & Población Urbana \\
\hline 2 & Industrial & 11 & Trabajadores y propiet & ios ind & ustriales & & \\
\hline & & 12 & Terratenientes & & & 14 & Agricultores \\
\hline 3 & Agricola & 13 & Pequeños propietarios & la tierr & & & \\
\hline 4 & Ganadero & 15 & Ganaderos & & & & \\
\hline 5 & Comercial & 16 & Comerciantes & & & & \\
\hline 6 & Turístico & 17 & Turistas y agentes turís & & & & \\
\hline 7 & Servicios públicos & 18 & Religiosos & & & 19 & Militares y fuerzas del orden \\
\hline & & adic: & dores para el sub & actor & vulne & abili & dad biofísica \\
\hline 1 & Anegamiento y enta & arquin & amiento de los terrenos & 12 & Daños a & a agric & ultura \\
\hline 2 & Daños en infraestruc & cturas & contra riadas* & 13 & Daños a & a gana & dería \\
\hline 3 & Daños en infraestruc & cturas & de riego & 14 & Incendi & fores & ales ** \\
\hline 4 & Daños comunicacior & nes $(\mathrm{p}$ & uentes, caminos, etc.) & 15 & Problen & $\mathrm{sde} \mathrm{c}$ & ontaminación ambiental ** \\
\hline 5 & Fallos en los sistema & a ener & géticos & 16 & Sobreex & lotaci & in de acuíferos ** \\
\hline 6 & Cambios en el curso & o de lo & s ríos & 17 & Problen & s se se & guridad alimentaria \\
\hline 7 & Problemas abastecin & mientc & doméstico de agua & 18 & Increme & to de 1 & os conflictos sociales \\
\hline 8 & Problemas de abaste & ecimie & nto de agua para riego & 19 & Dañose & onómi & cos generales \\
\hline 9 & Fallecidos y heridos & & & 20 & Empeor & mients & del estado sanitario \\
\hline 10 & Inundación de vivier & ndas $y$ & edificios* & 21 & Impacto & sociod & emográfico \\
\hline 11 & Pérdida de enseres $n$ & materi & ales* & 22 & Problen & $s$ final & cieros \\
\hline
\end{tabular}

Revista de Historia Moderna, n. ${ }^{\circ} 35$ (2017) (pp. 308-344) | ISSN-e: 1989-9823 | ISSN: 0212-5862 
Deconstruyendo riesgos. Cuatro siglos de cambios en la vulnerabilidad y adaptación a las inundaciones y sequías en Murcia

\begin{tabular}{|c|c|c|c|c|c|}
\hline \multicolumn{6}{|c|}{ Indicadores para el factor estrategia de adaptación y resiliencia } \\
\hline & $\begin{array}{c}\text { Indicadores } \\
\text { generales }\end{array}$ & \multicolumn{2}{|r|}{ Medidas no implementadas (propuestas) } & \multicolumn{2}{|r|}{ Medidas implementadas } \\
\hline \multirow{4}{*}{1} & \multirow{4}{*}{$\begin{array}{c}\text { Medidas para } \\
\text { la reducción } \\
\text { de la } \\
\text { vulnerabilidad } \\
\text { biofísica }\end{array}$} & 1 & $\begin{array}{l}\text { Incremento y mejora del abastecimiento } \\
\text { de agua }\end{array}$ & 1 & $\begin{array}{l}\text { Incremento y mejora del abastecimiento de } \\
\text { agua }\end{array}$ \\
\hline & & 2 & $\begin{array}{l}\text { Programas para traer agua a las } \\
\text { poblaciones }\end{array}$ & 2 & Programas para traer agua a las poblaciones \\
\hline & & 3 & Mejora de las infraestructuras de defensa & 3 & Mejora de las infraestructuras de defensa \\
\hline & & 4 & Mejoras en el sistema de riego & 4 & Mejoras en el sistema de riego \\
\hline \multirow{3}{*}{2} & \multirow{3}{*}{$\begin{array}{l}\text { Medidas para } \\
\text { la reducción } \\
\text { de la } \\
\text { vulnerabilidad } \\
\text { social }\end{array}$} & 5 & $\begin{array}{l}\text { Aplicación de materiales, técnicas de } \\
\text { construcción y edificación mejor } \\
\text { adaptadas }\end{array}$ & 5 & $\begin{array}{l}\text { Aplicación de materiales, técnicas de } \\
\text { construcción y edificación mejor adaptadas }\end{array}$ \\
\hline & & 6 & $\begin{array}{l}\text { Mejoras de calidad de vida, salubridad y } \\
\text { vivienda para sectores desfavorecidos }\end{array}$ & 6 & $\begin{array}{l}\text { Mejoras de calidad de vida, salubridad y } \\
\text { vivienda para sectores desfavorecidos }\end{array}$ \\
\hline & & 7 & Medidas higiénicas & 7 & Medidas higiénicas \\
\hline \multirow{5}{*}{3} & \multirow{5}{*}{$\begin{array}{l}\text { Medidas para } \\
\text { la reducción } \\
\quad \text { de la } \\
\text { exposición }\end{array}$} & 8 & $\begin{array}{l}\text { Creación de nuevos espacios habitables } \\
\text { en lugares más seguros }\end{array}$ & 8 & $\begin{array}{l}\text { Creación de nuevos espacios habitables en } \\
\text { lugares más seguros }\end{array}$ \\
\hline & & 9 & Regulación de usos del suelo & 9 & Regulación de usos del suelo \\
\hline & & 10 & $\begin{array}{l}\text { Medidas de gestión (nueva distribución y } \\
\text { reparto de agua, establecimiento de } \\
\text { tandas y turnos excepcionales, corte de } \\
\text { aguas programados, etc.) }\end{array}$ & 10 & $\begin{array}{l}\text { Medidas de gestión (nueva distribución y } \\
\text { reparto de agua, establecimiento de tandas y } \\
\text { turnos excepcionales, corte de aguas } \\
\text { programados, etc.) }\end{array}$ \\
\hline & & 11 & $\begin{array}{l}\text { Cambios en la organización } \\
\text { administrativa }\end{array}$ & 11 & Cambios en la organización administrativa \\
\hline & & 12 & $\begin{array}{l}\text { Expropiación de terrenos altamente } \\
\text { expuestos al peligro }\end{array}$ & 12 & $\begin{array}{l}\text { Expropiación de terrenos altamente expuestos } \\
\text { al peligro }\end{array}$ \\
\hline \multirow{5}{*}{4} & \multirow{5}{*}{$\begin{array}{l}\text { Medidas } \\
\text { económicas }\end{array}$} & 13 & Peritaje de daños para compensación & 13 & Peritaje de daños para compensación \\
\hline & & 14 & Facilidad de crédito & 14 & Facilidad de crédito \\
\hline & & 15 & Incentivos económicos & 15 & Incentivos económicos \\
\hline & & 16 & Ayudas a la agricultura & 16 & Ayudas a la agricultura \\
\hline & & 17 & Ayudas a otros sectores afectados & 17 & Ayudas a otros sectores \\
\hline \multirow{4}{*}{5} & \multirow{4}{*}{$\begin{array}{l}\text { Medidas para } \\
\text { prevenir } y \\
\text { evadir el } \\
\text { peligro natural }\end{array}$} & 18 & $\begin{array}{l}\text { Provisiones presupuestarias ante } \\
\text { emergencias }\end{array}$ & 18 & Provisiones presupuestarias ante emergencias \\
\hline & & 19 & $\begin{array}{l}\text { Educación ambiental ante la percepción } \\
\text { al riesgo }\end{array}$ & 19 & $\begin{array}{l}\text { Educación ambiental ante la percepción al } \\
\text { riesgo }\end{array}$ \\
\hline & & 20 & Mejora en los sistemas de alerta & 20 & Mejora en los sistemas de alerta \\
\hline & & 21 & $\begin{array}{l}\text { Medidas de optimización y adaptación } \\
\text { de la demanda de recursos a la oferta }\end{array}$ & 21 & $\begin{array}{l}\text { Medidas de optimización y adaptación de la } \\
\text { demanda de recursos a la oferta }\end{array}$ \\
\hline 6 & $\begin{array}{l}\text { Propuestas de } \\
\text { cambio } \\
\text { indefinidas }\end{array}$ & 22 & Petición de solución no especificada & 22 & Petición de solución no especificada \\
\hline
\end{tabular}

* Indicadores específicos de inundaciones. ** Indicadores específicos de sequías.

Fuente: Elaboración propia

Revista de Historia Moderna, n. 35 (2017) (pp. 308-344) | ISSN-e: 1989-9823 | ISSN: 0212-5862 